\title{
GLITCH: NOTACIONES PARA TEJER CON LO QUE DESAPARECE ${ }^{1}$
}

\author{
MARÍA Bella \\ Investigadora independiente
}

\begin{abstract}
Como investigadora y comisaria, he tratado de acentuar ciertos entrecruzamientos que acontecen entre las esferas del trabajo, la tecnología y el arte y desde ellos problematizar cómo el capitalismo transforma la vida en plusvalor. En este texto volveré a recorrer composiciones relacionadas con estas esferas intentando desprenderme de lo que el trabajo produce bajo los imperativos del capital. Escribiré como mujer que incorpora notaciones en las aperturas y ocultamientos de la trama de un tapiz común. Enhebraré hilos que, sin formar pieza con la máquina productiva, generen patchworks simbólicos y biopolíticos con los que, como los glitches, interrumpir los flujos lineales de las vidas enajenadas por el capital.
\end{abstract}

PALABRAS CLAVE: tejer, mujeres, trabajo, arte, tecnología.

\section{Glitch: Annotations for Weaving with Something that Disappears}

As researcher and curator, I have been interested in highlighting certain interrelations between the spheres of work, technology, and art as a way to problematize how capitalism has transformed life into surplus-value. In this text I will explore again works related to these spheres trying to detach myself from what labour produces under the imperatives of capital. I will write as a woman who incorporates notations both in the openings and concealments of the weave of a common tapestry. I will thread strings that, without becoming one piece with the productive machine, generate symbolic and biopolitical patchworks with which, like glitches, we may hope to interrupt the lineal flow of the lives estranged by capital.

KEY WORDS: weaving, women, work, art, technology.

\footnotetext{
${ }^{1}$ En el ámbito de la informática o los videojuegos, un glitch es un error que, al no afectar negativamente al rendimiento, jugabilidad o estabilidad del programa o juego en cuestión, no puede considerarse un fallo, sino más bien una característica no prevista. Algunos autores como Alexander R. Galloway (2004: 121) refieren al ciberfeminismo como un glitch, como un error que interrumpe el funcionamiento "normal" de la máquina.
}

Bella, María (2021), "Glitch: notaciones para tejer con lo que desaparece”, Lectora, 27: 177-190. ISSN: 1136-5781 D.O.I.: 10.1344/Lectora2021.27.8, mariabellabuschmann@gmail.com Recepció: 27 de novembre de 2020 - Acceptació: 21 d'abril de 2021 
Hilar es una ocupación deliciosa y suavemente relajante. Al hacerlo, te das cuenta de por qué el cross-patch, el cross-patch de la vieja canción de cuna aconseja "sentarse junto al fuego e hilar". Ningún malestar puede sobrevivir por mucho tiempo con ese tratamiento. El zumbido de la rueda, el movimiento rápido de la cinta que impulsa el huso y el hilo fino y liso al pasar entre el índice y el pulgar, brindan una maravillosa sensación de bienestar. -Mary Meigs Atwater, The Shuttle Book of American Hand Weaving (1951)

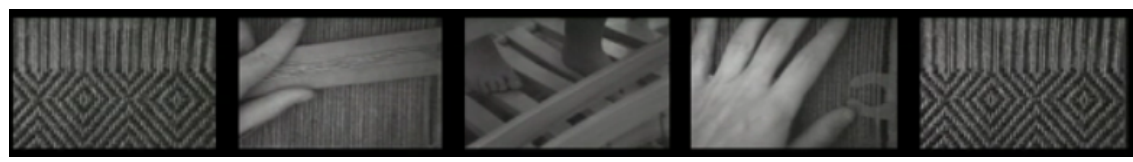

Fig. 1: Korot, Beryl (1976-1977), Text and Contemporary. Captura del vídeo. Disponible en $<$ https://vimeo.com/38061220>.

\section{Primera pasada}

Desde los distintos relatos mitológicos de nuestras culturas hemos aprendido que el hilo nos conecta con la vida mientras que las herramientas para producirlo - la rueca y el huso- o para tejerlo - el telar - simbolizan atributos poderosos. En la mitología griega el hilo, la rueca y el huso están en manos de Moira, deidad personificada por tres diosas que hilan el hilo de la vida. Una cuida de la parte del hilo que ya está formado, otra de la parte que se está trabajando y, la tercera, de la parte que queda por hilarse. Cloto, la hilandera, es el presente y asiste al nacimiento de los humanos portando el huso, ya que hilando nos orienta en los destinos. Láquesis, la parte asignada, es el futuro y sostiene la rueca porque a todas las cosas les espera una asignación. Átropo, sin vuelta, lleva unas tijeras y refiere a las cosas irreversibles (Graves, 1992: 10; Hart, 2005: 127-128; Müller, 2015).

Según cuenta Platón sobre la estructura del universo en la República (2019: 222), las Moiras son hijas de Ananké (Necesidad) surgida de la nada al principio de los tiempos, creadora del cosmos junto a Kronos, fuerzas del destino y el tiempo que rodean el universo; figura que se vale del huso para sostener de un extremo la tierra y del otro el cielo. Entre otras deidades tejedoras y demiurgas está Neith (Hart, 2005: 100-101), egipcia en origen y genealógicamente unida a la deidad griega Atenea, ambas guardianas de la guerra y espíritus de la inteligencia, alquimia "resultante del entrecruzamiento de sensaciones percibidas por medio de los órganos sensoriales tal y como los hilos se entrecruzan al tejer" (Lamy, citada por Plant, 1995: 55). En los relatos mitológicos de las tribus indígenas de América, la 
fuerza y el poder mágico o espiritual que permite que las cosas pasen es atribuido a la Abuela Araña (Grandmother Spider) (Allen, 1990, 2011). Así, las distintas tradiciones ancestrales muestran referencias a poderes de gran calado, como la creación o el destino de lo humano, que son encarnados por diosas femeninas y respaldados por atributos como telares. También refieren a casos de poderes menores en los que igualmente se pone en juego la vida y en los que las mujeres recurren al hilo como técnica simbólica o proceder alternativo. El hilo no es solo símbolo de comienzo sino que también indica que todavía hay vida que debe de seguir una y otra vez tejiéndose (Weissberg, 2010: 665). Vemos por ejemplo a la diosa Ariadna, ${ }^{2}$ que se vale del hilo para ayudar a Teseo a salir del laberinto tras vencer al Minotauro, o historias con actores no humanos como la de la niña Aracne convertida en araña, tejedora magistral de los pequeños rincones de la casa.

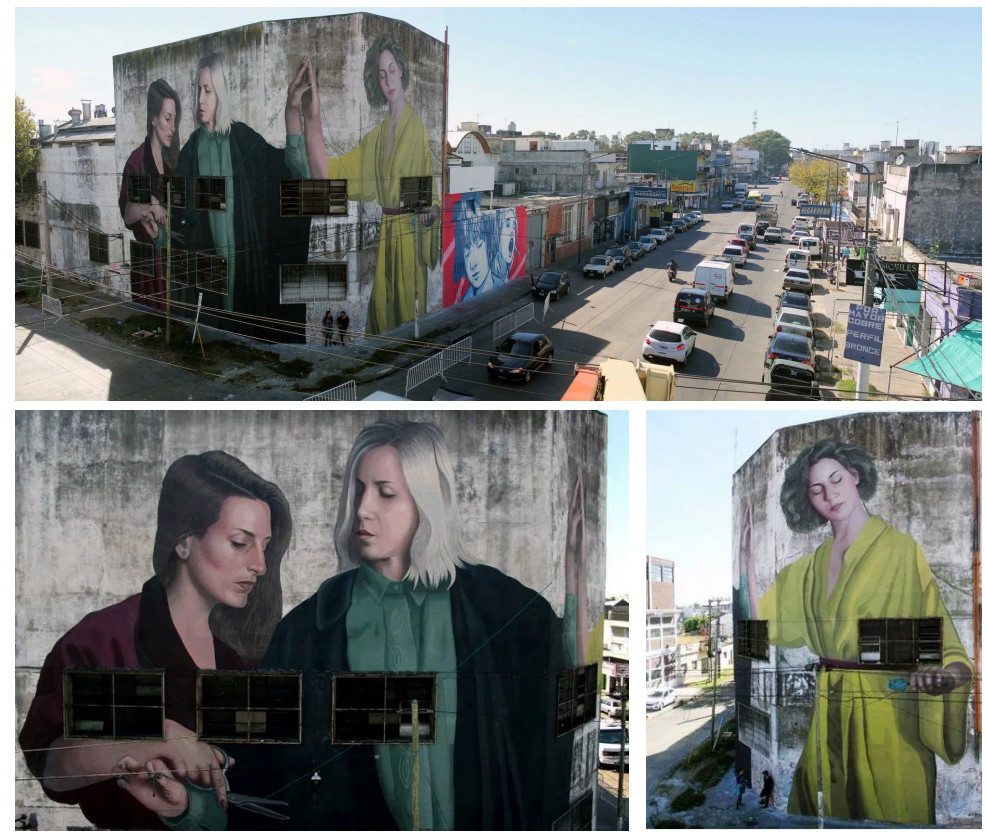

Fig. 2: Colectivo Licuado (2017), Las hiladoras. Fotografía del mural realizado en el marco del Festival Trama. Buenos Aires, Argentina. Disponible en $<$ https://www.colectivolicuado.com $>$.

\footnotetext{
${ }^{2}$ Aunque existen dudas sobre si Ariadna es propiamente una diosa, autores como James Vogh defienden que tanto Ariadna (tejedora) como Aracne (Araña) son Diosas de Creta y, algunas voces expertas como Mihoko Suzuki, J. H. Miller o Robert Graves, sugieren que ambas están relacionadas y refieren de hecho a la misma diosa araña. Ver Sullivan Kruger, 2001: 74.
} 
En la Teogonía, obra poética de Hesíodo que contiene una de las versiones más antiguas sobre el origen del cosmos y el linaje de los dioses, la Moira se enuncia como fuerza anterior a hombres y dioses, incluido Zeus, el rey de entre todas las figuras divinas. En dicho relato Moira toma parte en el origen y desarrollo del cosmos, en las divisiones en regiones, partes y elementos y su dictado debe ser obedecido sin excepción (Müller, 2015: 32-36). Estas referencias a una Moira tan poderosa provienen de una época temprana en la que los mitos se transmitían de manera oral a través de cantos o poemas; en textos posteriores como la Odisea, su relevancia quedará mermada y Zeus ganará terreno apropiándose de sus atributos, manejando él los destinos de las personas (Müller, 2015: 37). Así Moira empezará a ser nombrada solamente como Átropo, tomando la parte por el todo, contribuyendo a que la labor de esta diosa trínica, en origen creadora, se reduzca a algo tan abrupto como es interrumpir la vida: cortar el hilo y de este modo olvidar el resto de las tareas, inclusive la de tejer. ¿Cuánta potencia femenina habrá sido sustraída de los mitos, relatos centrales para la formación de la identidad y la cultura? Paula Gunn Allen reclama sustracciones similares en los mitos de los pueblos indígenas de América:

Con la llegada de los europeos, se precipitaron ciertos cambios en las tradiciones que habían estado ocurriendo durante los tres o cuatro siglos anteriores, desencadenando una ráfaga de ajustes [...] [incluido] el cambio lento del ordenamiento femenino con arreglos masculinos [...]. La transformación de Ic'sts'ity (Uretsete) de un femenino a un masculino sobrenatural, de madre a padre de la gente de Keres. $(1991: 165)^{3}$

Restarle facultades a Moira para ponerlas en manos de Zeus es un cambio de relato sustancial que irá dejándose ocultar a la par que es reforzado. En el mismo poema de la Odisea, el célebre Homero relatará las vidas de un héroe y de una heroína, una historia de acción en el caso de él y de espera en el de ella. Ulises, rey de Ítaca, combate en la guerra de Troya y supera innumerables pruebas adversas con el fin de reunirse con su amada Penélope. Mientras Ulises hace: "sobrevive a Scila y Caribdis, ciega a Polifemo, se enfrenta a las brujas y sirenas, lucha, ama y viaja sin parar" (Rico, 2017: 230), Pénelope espera: “permanece inmóvil' noche y día, durante veinte años, delante de un telar" (2017: 230). La variedad de actividades, movimientos y escenarios de las proezas masculinas llevan a pensar - como señala Santiago Alba Rico en Ser o no ser (un cuerpo) (2017) - que Ulises es y hace más que Penélope, que "solo" teje. El relato dificulta invertir los roles para preguntarnos ¿qué hubiera hecho Ulises para dar tiempo a Penélope? Penélope, cuyo

\footnotetext{
${ }^{3}$ Todas las citas en el texto cuya fuente está referida en inglés han sido traducidas al castellano por la autora.
}

180

Lectora, 27 (2021): 177-190. ISSN: 1136-5781 D.O.I.: 10.1344/Lectora2021.27.8 
nombre refiere precisamente a la trama y la urdimbre del telar (Graves, 1992), lejos de permanecer inmóvil, se ocupa tejiendo de día y destejiendo de noche. Homero cuenta, a través de la voz de la heroína, cómo esta teje durante años una tela funeraria larga y de hilo fino para Laertes, padre de Ulises. Remite incluso de forma genérica a los diseños pero no describe ni una sola de sus imágenes, convirtiendo el tapiz en una "tela silenciosa" (Homero, 1967: 19, 138-155; Sullivan Kruger, 2001: 80-81). Más que preguntarnos cómo Ulises nos da tiempo, deberíamos autorizarnos a nosotras mismas a imaginar y hacer visible lo que Penélope tejía en todos esos años a la espera de su amado. Lo que produce Penélope en su telar se ha convertido, sobre todo, en una imagen no representada, ${ }^{4}$ un relato no compartido, una expresión no transferida. Una especie de glitch que retorna como un déjà vu sustrayendo lo posible o reduciéndolo a la invisibilidad: a un no ser que ocupa espacio y tiempo mas se registra como un error descartable. El telar puede sernos útil para situar y materializar las acciones de desposesión que recorren nuestras vidas a la par que hacer visibles esos "fabulosos dragones [de los tapices] que deben de mantenerse vivos de algún modo para inspirarnos [a las mujeres] de nuevo en el futuro. [...] que vivan, cuando la memoria falte, en las historias que tejen las mujeres" (Broude y Garrard, 1994: 101).

\section{Entrecruzamientos}

Sacar el telar fuera de la casa para introducirlo en la fábrica como elemento esencial para el desarrollo del trabajo industrial en los "palacios encantados" (Dickens, 2004: 63-68, 78) activa de nuevo un glitch con el que visualizar otro cambio de relato sustancial. Mover el telar supuso una rearticulación radical de lo que venía siendo el espacio doméstico productivo y reproductivo de la casa/taller/tierra que se concebía como unidad para el sustento de la vida y cuya medida cuantificadora se basaba en lograr un equilibrio entre la necesidad y la capacidad de los cuerpos. Bajo este orden tejían ellos y tejíamos nosotras, pero además, a la mujer, el trabajo productivo de tejer en casa le favorecía para atender al trabajo reproductivo de cuidar solapándose ambos una y otra vez (Parker, 1996: 46-47). El movimiento

\footnotetext{
${ }^{4}$ Como hemos comentado, en la Odisea, Homero no especifica lo que Penélope teje de día y desteje por la noche y por lo tanto se desconocen las características de lo representado. La escena de Penélope frente al telar se ha recreado posteriormente en obras de arte y a veces supliendo esa imagen ausente (ver, por ejemplo, Penélope, 1896 del artista Max Klinger). La escena aparece también en algunas vasijas griegas conservadas que datan aproximadamente del año 430 a.C., siendo el Skyphos Chiusi la más conocida. En esta última pueden verse los motivos de la franja superior del tapiz; sin embargo, algunos estudios señalan la imposibilidad técnica de que estos fueran realizados con el tipo de telar que se enseña en la vasija (Harlizius-Klück y Fanfani, 2016: $68)$.
} 
moderno hacia las fábricas, además de alienarnos, dificultó las tareas de cuidado y nos obligó a sobrevivir menospreciando la potencia heredada de Moira. Tejer en los telares industriales suponía maltratar el hilo con el que se teje la vida y, a su vez, desatender el hilo que une una vida a la siguiente. Pero lo que está por sustraerse es, si cabe, todavía más complejo. Si tomamos las figuras de Ulises y Penélope y las trasladamos al contexto de producción moderna cuyo símbolo por excelencia es la fábrica y todo lo que en ella se organiza y reorganiza, puede verse que, dependiendo de cómo el telar se acopla, la potencia de tejer la vida se pierde bajo el poder que continuamente la sustrae. A medida que avance la Revolución Industrial y, con las fábricas llenas de telares, las mujeres volveríamos a dejar de tejer relegadas a lo que las teóricas marxistas-feministas como Silvia Federici han llamado el "patriarcado del salario" (2018). Entre los mecanismos que se incorporan en la segunda mitad del siglo XIX para favorecer la acumulación del capital, Federici incluye la creación del salario familiar dirigido al obrero masculino. Esta medida rechaza la productividad femenina y expulsa a las mujeres a los trabajos de reproducción no asalariados perpetuando un modelo de familia nuclear donde la mujer

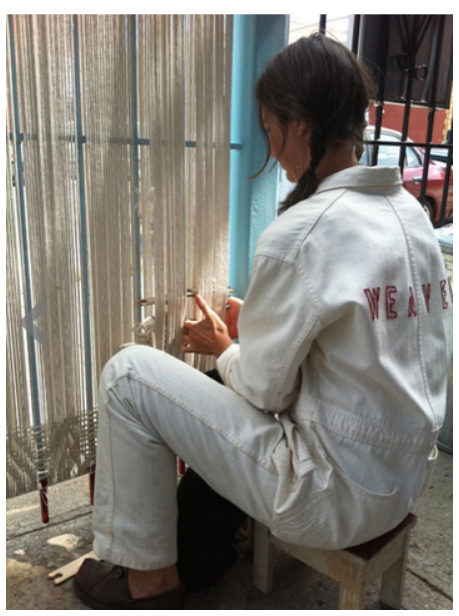

Fig. 3: Bervin, Jen (2011) Weaving at Gridspace. Fotografía de la instalación realizada tejiendo durante un mes. Disponible en <http://jenbervin.com/ projects/weaving-at-gridspace $>$. solo podrá ser un sujeto dependiente (Federici, 2018: 16-19). Al hilo de estas reflexiones, los telares podrían entenderse como aparato técnico/máquina/tecnología que sirvió para asentar los pilares de la producción industrial, de la mecanización, de la división y también de la desposesión; dándole tiempo a Ulises para producir un relato asalariado e invisibilizando el trabajo doméstico autónomo y de reproducción. Lo que Penélope tejía ya hemos dicho que no tiene representación y, sin embargo, sabemos que tejer nos da potencia aunque el poder la sustraiga para sí.

Si alguien en la Grecia antigua hubiera valorado lo que Penélope tejía, quizás no como trabajo pero al menos como obra artística - aunque luego fuera destejido-, hoy quedarían referencias sobre lo que sus tapices representaban. Aún en el supuesto de que estas fuentes nos hubiesen llegado, lo que Penélope tejía probablemente hubiera sido considerado "expresión de su feminidad" (Parker, 1996: 5) y en términos artísticos carecería de valor. Si ya en Grecia nadie proyectó su curiosidad especulativa para dar valor a lo tejido por un referente como el de Penélope, mujer de un héroe y heroína de las buenas esposas, los cambios que se 
articularían en la época moderna dificultarían todavía más que esto pudiera llegar a plantearse. Con el advenimiento de la Revolución Industrial, tejer pasará a ser principalmente una labor mecanizada y reproducible de manera masiva en los "palacios encantados", muy lejos de emparentarse con la pintura o la escultura producidas bajo la concepción elevada y singular del artista que produce la obra como un don. Desplazada de la fábrica a la casa, lo que tejen las mujeres en esta época dejará por tanto de tener valor industrial y tampoco alcanzará a tener valor artístico, es decir, no entrará en ninguno de los dos sistemas de producción de valor modernos (Bella, 2017, 2018a, 2018b). No será ni obra de arte ni tampoco trabajo asalariado. El poder de tejer quedará reducido a haber sido pieza técnica esencial para el desarrollo del aparato fabril y la producción alienada, generadores de plusvalor, esa cantidad de valor acumulado que luego puede ponerse en circulación en el mercado en cualquier momento. Todo lo demás será reproducción o producción amateur - por amor -5 que no se pone en circulación en la esfera pública sino en la esfera privada de lo doméstico. Así, el proceder moderno ha ido cercando nuestras posibilidades de habitar la esfera del trabajo, la de la tecnología y la del arte una y otra vez, quitándole el valor a aquello de lo que estábamos ocupándonos.

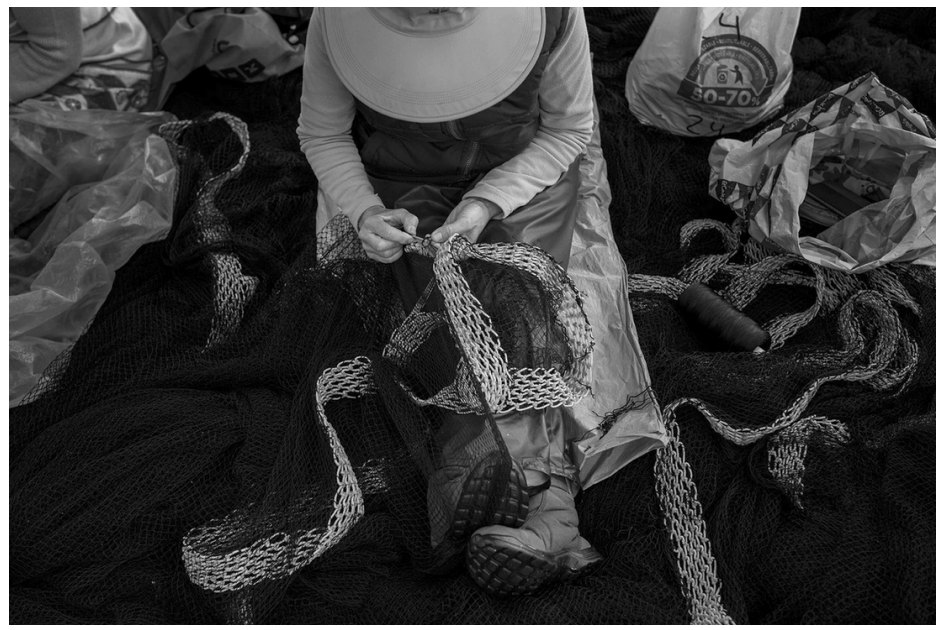

Fig. 4: Cambeiro, Alba (2019), Networkers. Fotografía perteneciente a la serie que reivindica el trabajo de las mujeres redeiras en Galicia. Cortesía de la artista.

\footnotetext{
5 "Amateur" viene de la raíz latina "amare", amar. Para obtener más información sobre el concepto, véase Knott, 2015.
} 
Durante esta larga época moderna y de progreso, muy marcada además por las estrategias de extractivismo colonial europeo, curiosamente la rueca y el hilo servirán a la India, colonia británica hasta 1947, como herramientas para abordar procesos de resistencia no solamente simbólica, sino también de reconstrucción real económica, social y cultural frente a la grave pérdida de autonomía y situación de dependencia a la que progresivamente se vieron avocados. India pasó de ser uno de los grandes productores textiles a situarse entre uno de los mayores consumidores de esta materia prima manufacturada. El imperio británico desplegó toda una infraestructura de importación de algodón que industrializaba en sus fábricas y que luego comercializaba de vuelta en el país asiático a precios elevados, borrando así las formas productivas e identitarias del país. Las distintas expresiones $\mathrm{y}$ articulaciones del movimiento swadeshi de la primera mitad del siglo XX en defensa de la preservación de los bienes propios de un país pusieron el foco justamente en la reactivación de la producción manual del tejido como modelo de resistencia frente al imperio, a la vez que como estrategia para la recuperación de la economía y la identidad. La reformulación del mismo movimiento en la etapa de lucha por la independencia llevó a inmortalizar la imagen de Gandhi sentado a la rueca, reivindicando el tejer como práctica productiva, política y espiritual e invitando a la ciudadanía a que la realizara en su día a día (Trivedi, 2007: xix-14). Tejer significaba recuperar los conocimientos y las formas de producción propias y locales frente a la imposición y extracción occidental que se iban imponiendo globalmente.

\section{Marcas para el paso del tiempo}

Es a un telar, concretamente el modelo híbrido técnico-tecnológico inventado por Jacquard a principios del siglo XVIII, hasta donde tenemos que retroceder para situar los primeros pasos de la invención del software cuyo objetivo último, en términos productivos, será el de migrar hacia las máquinas el control de las operaciones realizadas por humanos; empezando por la de tejer en las fábricas. La primera operación será una transferencia del control físico o de movimiento "mecánico" y lo facilitará el dispositivo de tarjetas perforadas, una especie de proto-software que "graba" las órdenes para realizar los patrones. Algo más tarde, este telar servirá de base al ingeniero Charles Babbage quien, con el apoyo de la poeta y matemática Ada Lovelace, diseñaría la "máquina analítica" con el objetivo de escalar la unidad de automatización trabajador-telar a toda la organización de la cadena productiva (De Landa, 1991: 155-162; Plant, 1998: 18-23). Tanto Babbage como Lovelace vivían ambos admirados por la grandeza de lo que esta máquina pondría entre sus manos, solo que "soñaban" sobre sus posibilidades de manera muy diferente. Babbage había escrito un amplio tratado sobre la organización del trabajo en las fábricas y sabía que la máquina podría proporcionar una gran eficiencia productiva.

184

Lectora, 27 (2021): 177-190. ISSN: 1136-5781 D.O.I.: 10.1344/Lectora2021.27.8 
Lovelace estaba apasionada por descubrir cómo las matemáticas y el pensamiento mediados por la máquina podrían aproximarla a los secretos del cosmos y de lo divino (Stein, 1984: 54-55). No será hasta el siglo XX, después de la Segunda Guerra Mundial, cuando gracias a Alan Turing y su desarrollo de la ACE (Automatic Computing Engine) se lograrán transferir estos procesos organizativos a un lenguaje de programación

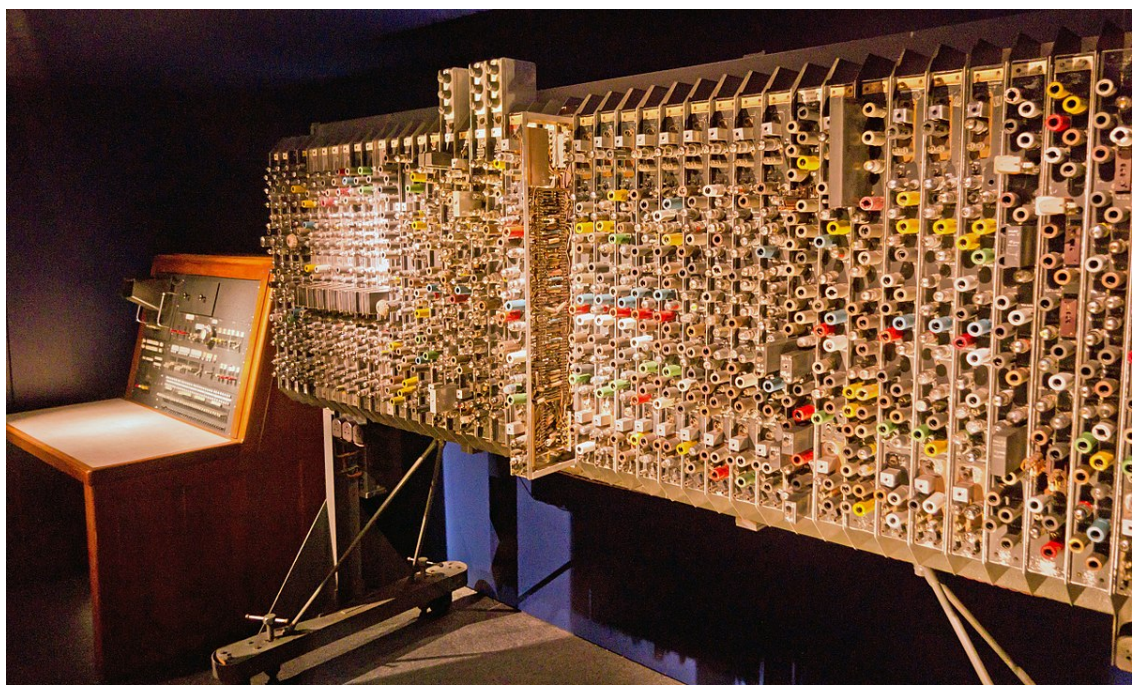

Fig. 5: Tavenaux, Antoine (2012). Fotografía del prototipo ACE expuesto en el Museo de Ciencias de Londres. Disponible en <https://commons.wikimedia.org/wiki/File:Pilot_ACE3.jpg>.

Después de la ACE irán incorporándose a este linaje hardwares cada vez más ligeros y softwares cada vez más inteligentes, aliados magistrales que formulados bajo la lógica del capital limitarán la vida a su capacidad de trabajo. Revoluciones técnicas y tecnológicas que anoto como hitos relevantes de una visión del mundo y de una realidad material que arrastra dos mil años de control patriarcal (Plant, 1995, 1998). Atenea, Penélope, Moira, Neith y Lovelace, todas emparentadas entre ellas como Abuelas Araña, son espíritus de otra inteligencia sustraída "resultante del entrecruzamiento de sensaciones percibidas por medio de los órganos sensoriales tal y como los hilos se entrecruzan al tejer" (Lamy, citada por Plant, 1995: 55). De nuevo serán mujeres tejiendo las que resistan la inercia imparable del patrón económico y tecnológico que avanzaría exponencialmente hacia la segunda mitad del siglo Xx. Enlazando con el resurgir de la artesanía, gracias al movimiento previo de los Arts and Crafts de finales del siglo XIX, las mujeres van a pelearse por un "tercer espacio" - a priori ni industrial ni doméstico- dentro de la pionera 
escuela de la Bauhaus. Sorprende pensar que en el marco innovador y experimental de este movimiento en el que se equilibraba la artesanía, el diseño y la industria, tejer fuera de nuevo un arte menospreciado, considerado como un medio carente de interés para la investigación artística y útil exclusivamente como recurso para obtener ingresos mercantiles (Smith, 2014: 32). Anni Albers, junto a sus compañeras de taller Gunta Stölzl y Helene Schmidt-Nonné, serían algunas de las voces que, a pesar de su débil posición en la escala de valor existente, construirían un cuerpo teórico con el que defender la merecida independencia y relevancia de tejer como una especialidad autónoma y de cualidades singulares tan valiosa como la pintura o la arquitectura. Su planteamiento no solo rescataba una práctica que se veía continuamente denostada por femenina y doméstica sino que, además, la dignificaría como un medio capaz de reaproximarnos a una "sensibilidad táctil"

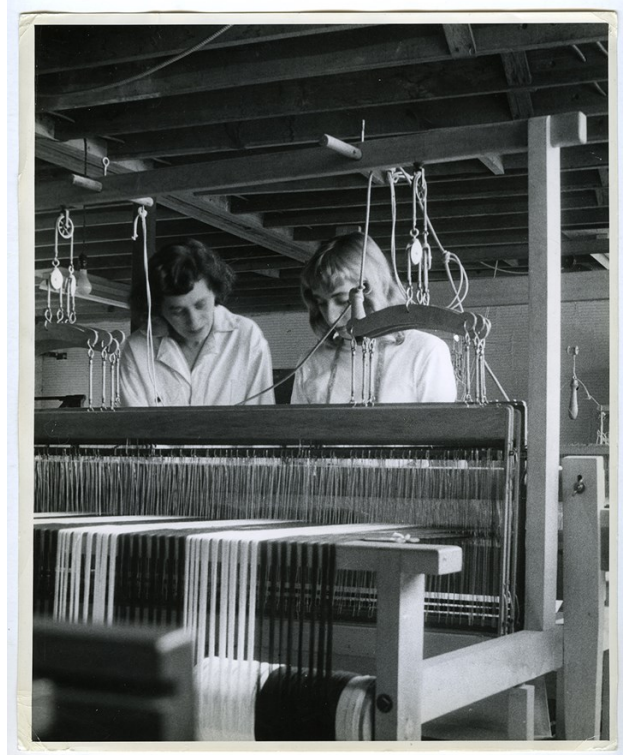

Fig. 6: Fotografía de Josef Breitenbach @ Josef and Yaye Breitenbach Charitable Foundation, Nueva York. Fotografía de Anni Albers y una estudiante en el telar en el Black Mountain College c. 1944.

Disponible en <https://i.ocula.com/anzax/content/ Reports\%2FAnni\%20Albers\%2FAnniAlbersandastud entattheloom_720_0.jpg>.
(Smith, 2014: 47-48) en un periodo en el que los procesos de producción de trabajo hacían cada vez más difuso el cuerpo y su sensibilidad material. Albers defendía "producir piezas textiles a través de un contacto holístico con el material intentando enseñar de nuevo esta sensibilidad mediante la exploración de todas sus posibilidades manuales y técnicas" (Albers, citada por Smith, 2014: 48). ${ }^{6}$

\section{La magia de tensar y soltar}

El arte feminista de los años setenta ha sido definido por la escritora y crítica Lucy Lippard no como un estilo ni como un movimiento, sino como "un sistema de valor", "una estrategia revolucionaria”, "una forma de vida" (Broude y Garrard, 1994: 10) que pondría en jaque la concepción moderna del mundo deconstruyendo las perspectivas excluyentes que habían ordenado los

\footnotetext{
${ }^{6}$ Para profundizar en la aproximación de Anni Albers sobre el tejer como práctica artística, especialmente desde una aproximación filosófica, puede consultarse Smith, 2015: 40.
}

186

Lectora, 27 (2021): 177-190. ISSN: 1136-5781 D.O.I.: 10.1344/Lectora2021.27.8 
relatos bajo posiciones eminentemente patriarcales tanto en el ámbito artístico como en el político y social. Lo que marcó la producción artística de las mujeres de esta época, frente a la de mujeres productoras de las décadas anteriores (las que formaron parte del expresionismo de los años cincuenta o del movimiento Arts and Crafts), fue la marcada autoconciencia a la que apelaban. En este nuevo sistema de valor sería crucial la reivindicación de las experiencias propias como distintas a las de los hombres y más aún la capacidad de autorizarse a indagar y a redefinir la identidad femenina que hasta ahora había sido construida por los otros (Broude y Garrard, 1994: 10-22). Una de las convocatorias colectivas que más ha marcado este espíritu, tanto de autoconciencia femenina individual como de grupo, es el proyecto llevado a cabo por Judy Chicago y Miriam Schapiro junto a las estudiantes del Feminist Art Program del California Institute of Arts. El colectivo de mujeres que participaba en este proyecto con obras, instalaciones, performances, charlas y otras experiencias toman la iconografía tradicional femenina para volver a socializarla y politizarla por medio del arte con el fin de "liberarla". Este grupo de mujeres sitúan su escenario de trabajo, de expresión artística y de visibilización social y política en la casa, reclamándola como propia empezando por el nombre del proyecto: Womanhouse. Desde ella, una casa victoriana en Hollywood a punto de ser demolida, y distanciándose de la perspectiva moderna impuesta o de la no representación heredada, regresan consciente y simbólicamente al lugar desde donde tradicionalmente habíamos sostenido nuestras vidas y donde, en muchos casos, habíamos tejido. Desde ahí, estas mujeres transforman los iconos de opresión como la "lencería, las casas de muñecas, la ropa de mujer o el maquillaje" (Broude y Garrard, 1994: 25), entre los que encontraremos también el hilo con el que la artista Faith Wilding teje una "habitación útero" emulando en su forma los refugios ancestrales construidos por mujeres.

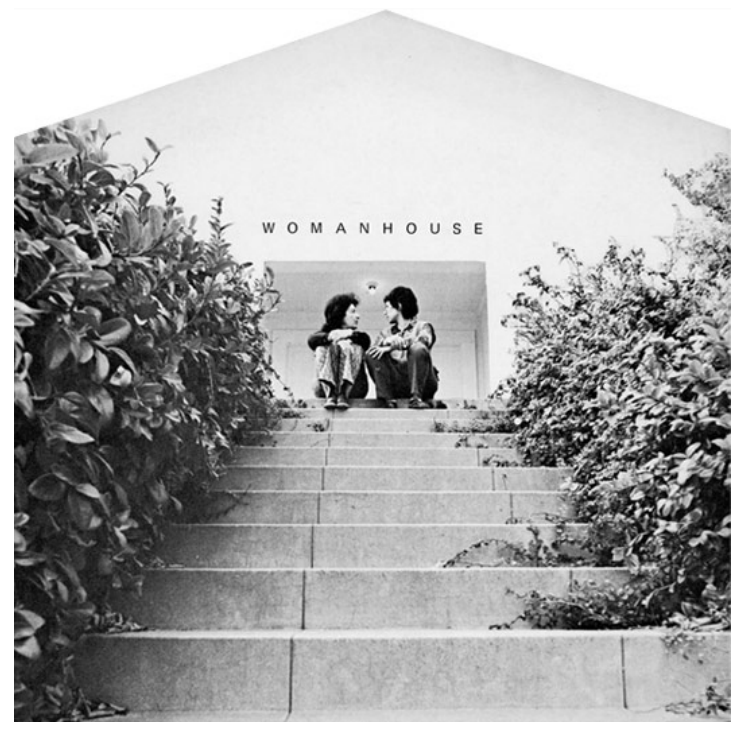

Fig. 7: Levrant de Bretteville, Sheila (1972). Portada del catálogo de la exposición Womanhouse. Disponible en $<$ https://commons.wikimedia.org/wiki/>. 


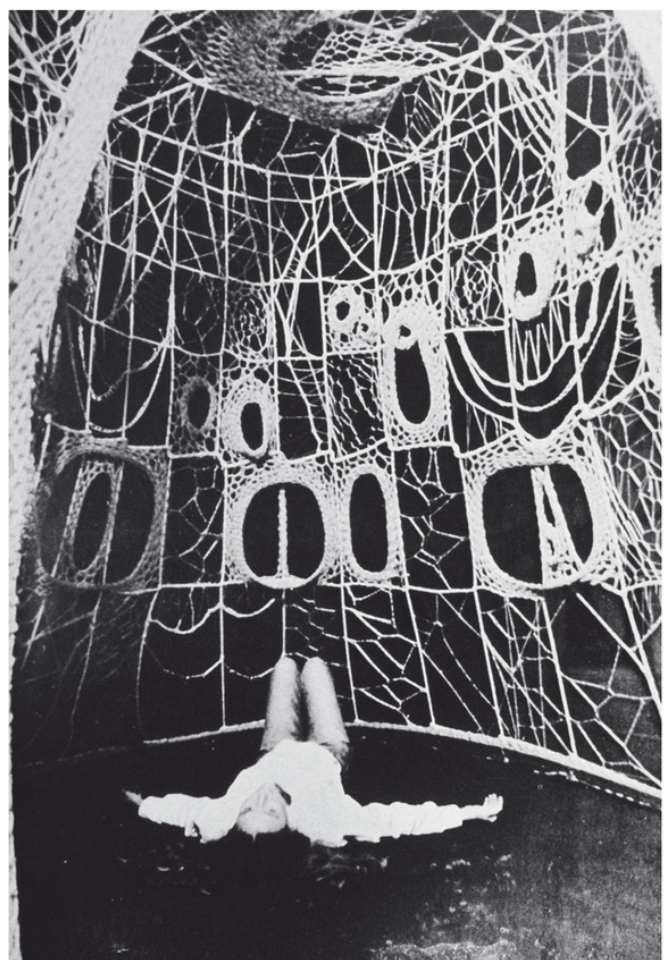

Fig. 8: Wilding, Faith (1972), Crochet Enviroment. Fotografía de la instalación realizada en Womanhouse. Imagen tomada de Chan, Grant y Mann (2013: 33).
Aprender a tejer en la antigua Grecia era fundamental para el aprendizaje femenino y representaba algo casi tan importante como el matrimonio; por eso Penélope tejía. El telar formaba parte de su espacio privado y tejer le aseguraba protección. Las mujeres no aprendían a leer ni a escribir y su manera de contar y comunicar estaba íntimamente relacionada con las piezas que elaboraban para uso propio, para regalos y ofrendas o para su venta (Sullivan Kruger, 2001: 74). Decía Albers que "junto a las pinturas rupestres el hilo es uno de los primeros transmisores de significado" (1974: 21), y tan antiguos como las pinturas rupestres, los tapices son los textos anteriores a la escritura, textos tejidos por mujeres. Por eso, además de ocultar los poderes y atributos de Moira y de hacernos parecer inmóviles mientras los hombres, luchan, vencen y comercian, cuando Homero "oculta” lo que teje Penélope hace desaparecer con sus textos nuestros textos. Debemos entender que tejer es expresión de nuestra inteligencia y reclamar que el telar sea también una herramienta tecnológica vinculada a nuestro lenguaje táctil y a nuestra espiritualidad. Pero aún más importante, no podemos olvidar que tejer es nuestro ritual común. Con él reconectamos con la Abuela Araña, la que permite que las cosas pasen. Somos sus parientas, las Nietas Araña, creadoras e interactuantes con los procesos naturales cuyos modos y tiempos sabemos que no controlamos. Es importante que nos concienciemos de que tejer nos hace "especialistas de lo reversible, nos permite hacer presente lo ausente, encontrar lo que está perdido, traer lo pasado y hacerlo actual. También podemos hacer que lo deshecho pueda volver a hacerse" (Plant, 1998: 25). Ahora que trabajo, tecnología y arte vuelven a restructurarse y que de algún modo hemos vuelto a nuestras casas, quizás sea importante seguir tejiendo. 


\section{REFERENCIAS BIBLIOGRÁFICAS}

Albers, Anni (1974), On Weaving, Londres, Studio Visa Publishers.

Atwater, Mary Meigs (1951), The Shuttle Book of American Hand Weaving, Nueva York, The Macmillan Company.

Bella, María (2017), "Ser crebeira”, Accesos, 1: 34-39.

-(2018a), "Nuevos imaginarios artísticos", Sin Objeto, 1: 68-83.

-(2018b), "Pensar la precariedad desde el arte", Trabajo en arte contemporáneo: precariedad y alternativas. Actas del I Congreso Internacional Prekariart, Bilbao, Universidad del País Vasco: 17-30.

Broude, Norma y Mary D. Garrard (1994), "Introduction: Feminist and Art in the Twentieth Century", The Power of Feminist Art: The American Movement of the 1970s, History and Impact, Norma Broude y Mary D. Garrard (eds.), Nueva York, Harry N. Abrams: 10-28.

Chan, Audrey; Alexandra Grant y Elana Mann (2013), "Rupture and Continuity in Feminist Re-performance", Afterall: A Journal of Art, Context and Enquiry, 33: 38-45.

De Landa, Manuel (1991), War in the Age of Intelligent Machines, Nueva York, Zone Books.

Dickens, Charles (2004), Hard Times for These Times, Adelaida, The University of Adelaide Library. [1854]

Federici, Silvia (2018), El patriarcado del salario. Críticas feministas al marxismo, Madrid, Traficantes de Sueños.

Galloway, R. Alexander (2004), Protocol. How Control Exists after Decentralization, Cambridge, Massachusetts \& Londres, The MIT Press.

Graves, Robert (2012), The Greek Myths: Volume One, Edimburgo, Penguin.

Gunn Allen, Paula (1989), Spider Woman's Granddaughters: Traditional Tales and Contemporary Writing by Native American Women, Nueva York, Ballantine Books.

-(1991), Grandmothers of the Light: A Medicine Woman's Sourcebook, Boston, Massachusetts, Bacon Press.

Harlizius-Klück, Ellen y Giovanni Fanfani (2016), “(B)orders in Ancient Weaving and Archaic Greek Poetry", Spinning Fates and the Song of the Loom. The Use of Textiles, Clothing and Cloth Production as Metaphor, Symbol and Narrative Device in Greek and Latin Literature, Marie Louise Nosch; Mary Harlow y Giovanni Fanfani (eds.), Oxford \& Philadelphia, Oxbowbooks: 61-100.

Hart, George (2005), The Routledge Dictionary of Egyptian Gods and Goddesses, Abingdon \& Oxon, Routledge. 
Homero (1967), The Odyssey, Richmond Alexander Lattimore (trad.), Nueva York, HarperCollins.

Knott, Stephen (2015), Amateur Craft. History and Theory, Bloomsbury, Londres, UK.

Müller, Moïra Anne (2015), Destino y libertad en el pensamiento antiguo, Tesis doctoral, Barcelona, Universidad de Barcelona. <http://hdl.handle.net /2445/67328>

Parker, Rozsika (1996), The Subversive Stitch: Embroidery and the Making of the Feminine, Londres, The Women's Press.

Plant, Sadie (1995), “The Future Looms: Weaving Women and Cybernetic”, Body \& Society, 1 (3-4): 45-64.

-(1998), Zeros and Ones: Digital Women and the New Technoculture, Londres, Fourth Estate.

Platón (2019), La república. Libro primero, Programa de Redes Informáticas y Productivas de la Universidad Nacional de General San Martín (UNSAM). $<$ https://circulosemiotico.files.wordpress.com/2019/03/platc3b3n-larepublica.pdf>

Rico, Santiago Alba (2017), Ser o no ser (un cuerpo), Barcelona, Seix Barral.

Smith, T'ai (2014), Bauhaus Weaving Theory. From Feminine Craft to Mode of Design, Minneapolis \& Londres, University of Minnesota Press.

-(2015), "The Event of a Thread", Textiles: Open Letter, Frank Rike y Grant Watson (eds.), Berlín, Sternberg Press: 36-47.

Stein, Dorothy K. (1984), "Lady Lovelace's Notes: Technical Text and Cultural Context", Victorian Studies, 28 (1): 33-67.

Sullivan Kruger, Kathryn (2001), Weaving the Word: The Metaphorics of Weaving and Female Textual Production, Londres, Associated University Presses.

Trivedi, Lisa (2007), Clothing Gandhi's Nation Homespun and Modern India, Bloomington, Indiana UP.

Weissberg, Liliane (2010), “Ariadne’s Thread”, Modern Languages Notes, 125 (3): 661-681. 